\title{
AD-0047 - Screening for diabetes mellitus and prediabetes among people of Uzbek nationality
}

Alieva A. ${ }^{\text {; }}$ Rakhimova G. 2 ; Ismailov S. ${ }^{3}$

${ }^{1}$ Republican Specialized Scientific-Practical Medical Centre of Endocrinology

2Tashkent Institute for Doctors' Postgraduate Education

${ }^{3}$ Tashkent Pediatric Medical Institute

Background and aim: Screening consisted of two according to WHO stages: 1) filling in the recommendations, active questionnaire of DM risk and screening for diabetes revealing of high DM risk; 2) mellitus (DM) should be oral glucose tolerance test with performed every 3 years. $75 \mathrm{~g}$ of glucose. DM and Previous epidemiological studies in Uzbekistan showed that true DM prevalence was 7 to 10 times higher comparing to the number of registered patients, so our aim was to study prevalence of carbohydrate metabolism disorders among people of Uzbek nationality.

Materials and methods: we performed screening for DM and prediabetes among urban and rural population of Uzbek nationality aged 35 and older, in 3 regions of the Republic of Uzbekistan. 2159 people were screened (67.8\% women).

$\%$ of obesity and overweight in men and women of Uzbek nationality with diagnosed DM2, IGT and IFG

\section{men}

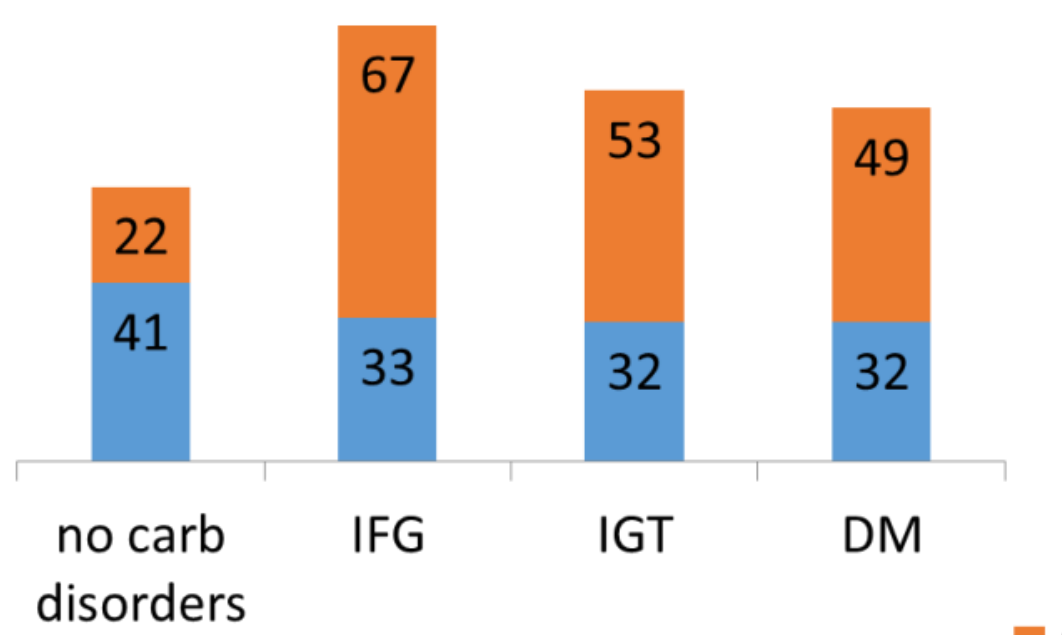

prediabetes were diagnosed according to IDF recommendations.

Results: Prevalence of DM was $8.3 \%, 71 \%$ of them were diagnosed during the screening (DM was newly diagnosed in
$5.9 \%$ of screened women and $5.9 \%$ of screened men). IFG was revealed in $1.1 \%$ (in $1.4 \%$ of women and $0.4 \%$ of men), IGT in $3.8 \%$ (in $4.2 \%$ of women and $2.7 \%$ of men). Relatively low prevalence of IGT comparing to DM is unclear. However, it is necessary to note, that $68.6 \%$ of screened individuals $(70 \%$ of women and $65.6 \%$ of men) were overweighed or obese (BMI > 25 $\mathrm{kg} / \mathrm{m} 2$ ).

\section{Prevalence of type 2 DM, IGT and IFG in Uzbekistan}

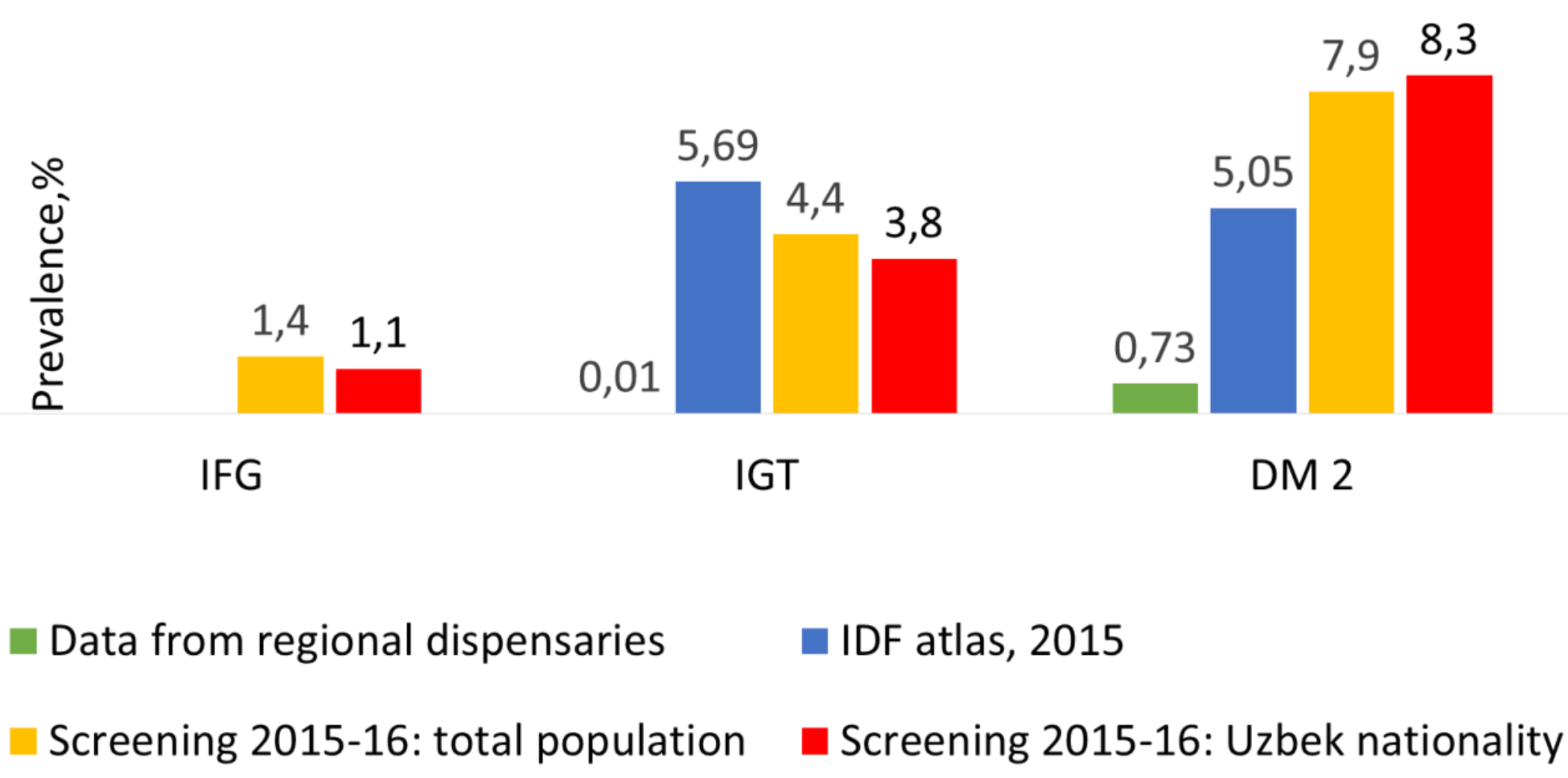

